\section{T1 \\ THE UNIVERSITY OF TENNESSEE \\ KNOXVILLE}

COLLEGE OF LAW

\title{
Two Artificial Neural Networks Meet in an Online Hub and Change the Future (of Competition, Market Dynamics and Society)
}

\author{
Maurice E. Stucke \\ \& \\ Ariel Ezrachi
}

\section{Do Not Cite Without Authors' Permission Copyright @ 2017}

This paper may be downloaded without charge from the Social Science Research Network Electronic library at: http://ssrn.com/abstract=2949434

Learn more about the University of Tennessee College of Law: law.utk.edu 


\title{
Two Artificial Neural Networks Meet in an Online Hub and Change the Future (of Competition, Market Dynamics and Society)
}

\author{
Ariel Ezrachi* \& Maurice E. Stucke ${ }^{* *}$
}

\section{Introduction}

In the future, one may imagine a new breed on antitrust humor. Jokes might start along the following lines: "Two Artificial Neural Network and one Nash equilibrium meet in an online (pub) hub. After a few milliseconds, a unique silent friendship is formed..."

Back to the present; we are not sure how this joke might end. Nor can we estimate how funny future consumers would find it. We can, however, explain, at present, how technological advancements have changed, and will continue to change, the dynamics of competition and subsequently the distribution of wealth in society. How algorithms may be used in stealth mode to stabilize and dampen market competition while retaining the façade of competitive environment.

That tale is at the heart of this paper.

We first raised algorithmic tacit collusion in $2015 .{ }^{1}$ In 2016 we provided further

\footnotetext{
* Slaughter and May Professor of Competition Law, The University of Oxford. Director, Oxford University Centre for Competition Law and Policy.

** Professor, University of Tennessee College of Law; Co-founder, The Konkurrenz Group. A version of this paper was submitted as background note to the OECD Roundtable on Algorithms and Collusion (Friday, 23 June 2017)

We are grateful for comments received from Rónán Kennedy and Ashwin Ittoo on the technical aspects of Neural Networks.

1 Ezrachi and Stucke, 'Artificial Intelligence \& Collusion: When Computers Inhibit Competition', Oxford Legal Studies Research Paper No. 18/2015, University of Tennessee Legal Studies Research Paper No. 267, available at SSRN: https://ssrn.com/abstract=2591874 or http://dx.doi.org/10.2139/ssrn.2591874.
} 
context and analysis in our book, Virtual Competition: The Promise and Perils of the Algorithm-Driven Economy. ${ }^{2}$ We illustrated how online tacit collusion may emerge when products are generally homogeneous and sellers do not benefit from brand recognition or loyalty, and when markets are transparent and concentrated.

In Part I of this paper we expand on the means through which algorithmic tacit collusion may appear. We examine the conditions for algorithmic tacit collusion and illustrate, using several recent economic studies, how an industry's shift to pricing algorithms can spread tacit collusion beyond duopolies to markets with five or six large firms. We further consider the joint dynamics of tacit and hub-and-spoke collusion, and explore the interplay between tacit collusion and price discrimination. We identify an additional hybrid scenario which facilitates simultaneously both tacit collusion and behavioral discrimination. In connecting three theories of harm - tacit collusion, hub-and-spoke, and behavioral discrimination - we highlight how in reality they can be used in parallel, depending on the market conditions.

Part II explores the challenges in tackling the algorithmic tacit collusion scenarios with the current enforcement tool kit. We note how some forms of intervention could, somewhat counter-intuitively, create, at times, new problems that reduce our welfare.

Part III moves beyond the traditional enforcement toolbox and proposes several counter-measures to undermine algorithmic tacit collusion, including an algorithmic tacit collusion incubator. The incubator enables competition officials to test the effects and likelihood of different counter-measures to destabilize conscious parallelism. This part also explores the use of counter-measures, which private and government entities may develop to benefit consumers.

2

HUP, 2016. See: http://www.hup.harvard.edu/catalog.php?isbn=9780674545472\&content=reviews. 


\section{Part I}

\section{Interlinked strategies - Algorithmic tacit collusion, hub-and-spoke and behavioural discrimination}

\section{I.i The rise of Algorithmic Tacit Collusion}

Humans may use technology and algorithms to support traditional forms of collusion - that is collusion agreed between humans and executed with the assistance of technology. ${ }^{3}$ From a legal and policy perspective, this scenario is unremarkable. Technology in this case does not affect the scope and application of the law.

We focus here on a more complex reality involving algorithmic tacit collusion (conscious parallelism) ${ }^{4}$ where the same anticompetitive outcome is achieved (namely higher prices) without rivals having agreed to tamper with prices. ${ }^{5}$

Algorithmic tacit collusion will not affect every (or even most) markets. As Virtual Competition explores, one would expect it in markets with several important characteristics:

3 'Price-fixing: guidance for online sellers', Competition \& Markets Authority (November 2016), available

https://www.gov.uk/government/uploads/system/uploads/attachment_data/file/565424/60ssprice-fixing-guidance-for-online-sellers.pdf; Jonathan Stempel, 'U.S. announces first antitrust ecommerce prosecution', Reuters (April 6 2015), available at http://www.reuters.com/article/ususa-antitrust-ecommerce-plea-idUSKBN0MX1GZ20150406.

${ }^{4}$ Brooke Group Ltd. v. Brown \& Williamson Tobacco Corp., 509 U.S. 209 (1993) (describing "the process, not in itself unlawful, by which firms in a concentrated market might in effect share monopoly power, setting their prices at a profit-maximizing, supracompetitive level by recognizing their shared economic interests and their interdependence with respect to price and output decisions and subsequently unilaterally set their prices above the competitive level.; R. S. Khemani and D. M. Shapiro, 'Glossary of Industrial Organisation Economics and Competition Law'. Paris Organisation for Economic Co-operation and Development, 1993, available at http://www.oecd.org/dataoecd/8/61/2376087.pdf.

5 Marc Ivaldi, Bruno Jullien, Patrick Rey, Paul Seabright, and Jean Tirole, 'The Economics of Tacit Collusion', Final Report for DG Competition (Toulouse: European Commission, March 2003), available

at http://ec.europa.eu/competition/mergers/studies_reports/the_economics_of tacit_collusion_en.pdf 
First, algorithmic tacit collusion would likely arise in concentrated markets involving homogenous products where the algorithms can monitor to a sufficient degree the pricing and other keys terms of sale. ${ }^{6}$ Conscious parallelism would be facilitated and stabilized by the shift of many industries to online pricing, as sellers can more easily monitor competitors' pricing, key terms of sale and any deviations from current equilibrium. In such an environment, algorithmic pricing provides a stable, predictable tool, which can execute credible and effective retaliation. Software may be used to report and take independent action when faced with price deviation, be it from the supra-competitive or recommended retail price.

A second important market condition is that once deviation (e.g., discounting) is detected, a credible deterrent mechanism exists. ${ }^{7}$ Unique to an algorithmic environment is the speed of retaliation. ${ }^{8}$ Computers can rapidly police deviations, and calculate the profit implications of myriad moves and counter-moves to punish deviations. ${ }^{9}$ The speed of calculated responses effectively deprives discounting rivals of any significant sales. The speed also means that the tacit collusion can be signalled in seconds. The greater the improbability that the first-mover will benefit from its discounting, the greater the likelihood of tacit collusion. ${ }^{10}$ Thus if each algorithm can

\footnotetext{
${ }^{6}$ Guidelines on the assessment of horizontal mergers under the Council Regulation on the control of concentrations between undertakings (2004/C 31/ 03), para 41.

7 Ibid, para 41.

8 Contrast this with Ibid, para 53 ("The speed with which deterrent mechanisms can be implemented is related to the issue of transparency. If firms are only able to observe their competitors' actions after a substantial delay, then retaliation will be similarly delayed and this may influence whether it is sufficient to deter deviation.")

9 Jill Priluck, 'When Bots Collude', The New Yorker (April 25 2015), available at http://www.newyorker.com/business/currency/when-bots-collude.

10 Samuel B. Hwang and Sungho Kim, 'Dynamic Pricing Algorithm for E-Commerce', in Advances in Systems, Computing Sciences and Software Engineering, Proceedings of SCSS05, Tarek Sobh and Khaled Elleithy, eds. (Dordrecht: Springer, 2006), 149-155; N. Abe and T. Kamba, 'A Web Marketing System with Automatic Pricing', Computer Networks 33 (2000): 775-788; L. M. Minga, Y. Q. Fend, and Y. J. Li, 'Dynamic Pricing: E-Commerce-Oriented Price Setting Algorithm', International Conference on Machine Learning and Cybernetics 2 (2003).
} 
swiftly match a rival's discount and eliminate its incentive to discount in the first place, the "threat of future retaliation keeps the coordination sustainable."11

A third condition is that "the reactions of outsiders, such as current and future competitors not participating in the coordination, as well as customers, should not be able to jeopardise the results expected from the coordination."12 Thus algorithmic tacit collusion will likely arise in concentrated markets where buyers cannot exert buyer power (or entice sellers to defect), sales transactions tend to be "frequent, regular, and relatively small," 13 and the market in general is characterized by high entry barriers.

The stability needed for algorithmic tacit collusion is enhanced by the fact that computer algorithms are unlikely to exhibit human biases. ${ }^{14}$ Human biases, of course, may be reflected in the programming code. But biases will not necessarily affect decisions on a case-by-case basis: a computer does not fear detection and possible financial penalties or incarceration; nor does it respond in anger. ${ }^{15}$ "We're talking about a velocity of decision-making that isn't really human," said Terrell McSweeny, a commissioner with the US Federal Trade Commission. "All of the economic models are based on human incentives and what we think humans rationally will do. It's entirely possible that not all of that learning is necessarily applicable in some of these markets." 16

11 EC Merger Guidelines (n 6), para 52.

12 EC Merger Guidelines (n 6), para 41.

13 US Horizontal Merger Guidelines 2006, available at https://www.justice.gov/atr/file/801216/download.

14 EC Merger Guidelines (n 6), para 44 (observing that "[c]oordination is more likely to emerge if competitors can easily arrive at a common perception as to how the coordination should work. Coordinating firms should have similar views regarding which actions would be considered to be in accordance with the aligned behaviour and which actions would not.")

15 Stucke and Ezrachi, 'How Pricing Bots Could Form Cartels and Make Things More Expensive', Harvard Business Review (October 27 2016), available at https://hbr.org/2016/10/how-pricingbots-could-form-cartels-and-make-things-more-expensive.

16 David Lynch, 'Policing the Digital Cartels', Financial Times (January 9 2017), available at http://www.pros.com/about-pros/news/financial-times-policing-digital-cartels/ 
When the above conditions are present, one would expect tacit collusion. Importantly, the nature of electronic markets, the availability of data, the development of similar algorithms, and the stability and transparency they foster, will likely push some markets that were just outside the realm of tacit collusion into interdependence. ${ }^{17}$

To be clear, no bright line exists when an industry becomes sufficiently concentrated for either express or tacit collusion. ${ }^{18}$ Generally, for illegal cartels involving express collusion which were detected and prosecuted, the empirical research has that cartels involving a trade association were on average over twice as large than cartels without a trade association involved. ${ }^{19}$ The belief is that express collusion generally

17 One would expect tacit collusion to be feasible with a larger number of participants than commonly assumed. On the common market assumptions, see generally R. Selten, 'A Simple Model of Imperfect Competition, Where Four Are Few and Six Are Many', International Journal of Game Theory 2 (1973): 141; Steffen Hucka, Hans-Theo Normannb, and Jörg Oechssler, 'Two Are Few and Four Are Many: Number Effects in Experimental Oligopolies', Journal of Economic Behavior and Organization (2004) 53(4) 435-446.

18 Note, for example, research by Levenstein and Suslow, who offer several explanations for the lack of a clear empirical relationship between industry concentration and cartels involving express collusion: "First, this ambiguity may reflect the bias introduced by focusing on cartels that were prosecuted by the U.S. Department of Justice; cartels with large numbers of firms or that had the active involvement of an industry association may have been more likely to get caught. Second, industries with a very small number of firms may be able to collude tacitly without resort to explicit collusion. Third, concentration is endogenous: collusion may have allowed more firms to survive and remain in the market." Margaret C. Levenstein and Valerie Y. Suslow, 'What Determines Cartel Success?', Journal of Economic Literature (2006) 44(1) at 4395. EconLit, EBSCOhost (accessed April 6, 2017).

19 One empirical analysis of successfully prosecuted cartels between 1910 and 1972 showed that cartels on average had many participants: where a trade association facilitated collusion, 33.6 firms was the mean of firms involved, and fourteen firms was the median; in price-fixing cartels (without a trade association involved), 8.3 firms was the mean and six was the median. Arthur G. Frass and Douglas F. Greer, 'Market Structure and Price Collusion: An Empirical Analysis', 26 J. Indus. Econ. 21, 25, 36-41 (1977). One conservative assumption in that empirical study was that the number of cartel members prosecuted reflected the total number of firms in the relevant market. (Ibid at 24). But, aside from ineffectual fringe firms, the relevant market may contain more participants than reflected in the government's indictment or criminal information, which does not always identify all the co-conspirators. Consequently, the authors had to exclude from its sample of 606 cases, those cases where the number of firms allegedly involved were not specified in the records (Ibid at 25-26). Some co-conspirators conceivably could escape prosecution (through lack of evidence). Although the authors rely upon an earlier study, which showed a 0.959 correlation between the number of conspirators and total number of firms in the market, the sample size of that earlier study was 34 cases (Ibid at 28, citing George Hay and Daniel Kelly, 'An Empirical Survey of Price Fixing Conspiracies', 17 J.L. \& Econ. 13 (1974)). For studies of 
represents the outer boundary. (Otherwise why would competitors expressly collude when they could tacitly collude legally?) One maxim is that tacit collusion is "frequently observed with two sellers, rarely in markets with three sellers, and almost never in markets with four or more sellers." ${ }^{20}$ Whether this is empirically true is another matter. ${ }^{21}$

Even if we accept the premise that tacit collusion is likelier in duopolies than triopolies and quadropolies, two factors should give us pause:

One factor is that state of competition in major economies, like the United States, is worrisome, with evidence of increasing concentration and greater profits flowing into fewer hands. ${ }^{22}$ Thus, if market concentration increases, more markets may be susceptible to tacit collusion.

cartels immunized from the antitrust laws, see, e.g., Andrew R. Dick, 'Identifying Contracts, Combinations \& Conspiracies in Restraint of Trade', 17 Managerial \& Decision Econ. 203, 213 (1996) (discussing that cartels are formed more frequently in unconcentrated industries under Webb-Pomerene Export Trade Act); see also Paul S. Clyde and James D. Reitzes, "The Effectiveness of Collusion Under Antitrust Immunity: The Case of Liner Shipping Conferences, Bureau of Economics Staff Report' (Dec. 1995) (finding a positive, but economically small, relationship between overall market concentration and shipping rates), available at https://www.ftc.gov/sites/default/files/documents/reports/effectiveness-collusion-under-antitrustimmunity-case-liner-shipping-conferences/232349.pdf; see also Maurice E. Stucke, 'Behavioral Economists at the Gate: Antitrust in the Twenty-First Century', 38 Loy. U. Chi. L.J. 513, 555-56 (2007) (collecting earlier empirical work on cartels in moderately concentrated and unconcentrated industries); Ibid at 58 (finding no simple relationship between industry concentration and likelihood of collusion); Margaret C. Levenstein and Valerie Y. Suslow, 'Breaking Up Is Hard to Do: Determinants of Cartel Duration', 54 J.L. \& Econ. 455 at 12 (finding international cartels prosecuted between 1990-2007 had on average 7.4 members).

20 J Potters,. and S Suetens (2013). 'Oligopoly experiments in the current millennium', Journal of Economic Surveys 27(3), 439-460.

${ }^{21}$ Niklas Horstmann, Jan Kraemer, and Daniel Schnurr, 'Number Effects and Tacit Collusion in Experimental Oligopolies' (October 24 2016). available at SSRN: https://ssrn.com/abstract=2535862 or http://dx.doi.org/10.2139/ssrn.2535862 (finding from the extant literature "no robust empirical evidence that would support this claim of a strictly monotonic relationship between the number of firms and the degree of tacit collusion in a given market," but finding this monotonic trend from their own two experiments).

22 See, e.g., Jonathan B. Baker, 'Market power in the U.S. economy today' (March 2017); Economic Innovation Group, 'Dynamism in Retreat: Consequences for Regions, Markets, and Workers' (February 2017); Gustavo Grullon, Yelena Larkin, and Roni Michaely, 'Are US Industries Becoming More Concentrated?' (Feb 23 2017), available at SSRN: https://ssrn.com/abstract=2612047 or http://dx.doi.org/10.2139/ssrn.2612047. 
A second factor is that the industry-wide use of algorithms, given the speed and enhanced transparency, could expand the range of industries susceptible to collusion beyond duopolies to perhaps markets dominated by 5 or 6 players, as we illustrate below.

Markets in which conscious parallelism was unstable or not present, may see a new equilibrium emerge, due to increased concentration, transparency, greater stability and effective punishment. Ultimately we are likely to see more instances in which similar pricing is not the result of fierce competition, nor the result of cartel activity, but rather the result of tacit collusion. With the use of algorithms, operators in these markets will find it possible and rational to weave the tacit collusion model into the algorithm. While they may use different technologies or algorithms, they will share an incentive to embed a stabilizing strategy in their algorithms.

\section{I.ii Online Technology and Offline Welfare Effects}

To illustrate the dynamic described above, imagine an oligopolistic market for petrol with limited transparency. The market includes a relatively few sellers and prices are only visible when reaching each petrol station. In this market, customers may be subjected to search costs, but could mitigate them by asking their friends about any available deals, visit a few stations, and support the one with the lowest price. Here a petrol station, by discounting, may increase its profits and develop a reputation for having a low (if not the lowest) price. At times, competitors, aware of the price reductions and promotions, would respond with their own initiative. But the limited transparency and delayed action are likely to benefit the discounter. Under these market conditions, conscious parallelism is harder to sustain. The firms will likely compete as expected. We see here how markets "need to be sufficiently transparent 
to allow the coordinating firms to monitor to a sufficient degree whether other firms are deviating, and thus know when to retaliate." 23

When transparency increases in concentrated markets with homogeneous goods, so too does the risk of tacit collusion. In what follows we consider three recent economic studies in three different continents where posting petrol prices online promoted tacit collusion.

\section{A. Chilean retail-petrol industry}

In February 2012, petrol stations had to post their fuel prices on a government website and to keep prices updated as they changed at the pump. An economic study found that this Chilean regulation softened, rather than increased, competition. ${ }^{24}$ The petrol stations' margins increased by $10 \%$ on average following the prices being posted on the government website. The softening of competition was common across brands, and was not limited to a single Chilean city. Interestingly, although the stations' margins increased across Chile, the effect was not uniform: the petrol station margins "increased the most in areas with low or non-existent consumer search (lowincome areas), while they increased the least, and even decreased, in areas with high search intensity (high-income areas)." 25

\section{B. Germany}

The German government suspected that an oligopoly of 5 firms -- BP (Aral), ConocoPhilipps (Jet), ExxonMobil (Esso), Shell, and Total - dominated the off-

\footnotetext{
${ }^{23}$ EC Merger Guidelines (n 6), para 49.

24 Fernando Luco, 'Who Benefits from Information Disclosure? The Case of Retail Gasoline', Working Paper, Department of Economics, Texas A\&M University September 28, 2016, available at https://cf00f56d-a-62cb3a1a-ssites.googlegroups.com/site/flucoe/home/Info disclosure.pdf?attachauth=ANoY7colGaf66bKWn0 h_BnbFaq4kHFB7rYJrb6vZVN6BhIZeTPbNs2LRUOiyuLeAP4jY8YXe3nuDW2dEE2wtLOd0Yi hxBS-4CB2hgafQqHf5auyPyq_DlPrThncKi7sNvnvXgXomB_Hk3ROwYLV9tZWtlWn5YfDAzjA69ARs8nxOrFEJzac5ULK2lBwGHkIO9QsN9sEdZfUnX1OjUL9J2qE_IWdgPuhA\%3D\%3D\&attredirec $\underline{\mathrm{ts}}=0$.

25 Ibid.
} 
motorway petrol station business. ${ }^{26}$ To monitor pricing, the petrol station owners would drive past specified competitor petrol stations several times a day and note their prices. The monitored prices were then fed into the respective oil company's electronic system. Generally, when one competitor increased petrol price, rivals generally would respond between three to six hours later. ${ }^{27}$

To promote competition, the government required the petrol stations to report to its government's transparency unit any price changes for gasoline or diesel fuel in "real time." 28 The government's transparency unit then transmitted the price data to consumers, with the aim that they could easily find the cheapest petrol nearby.

Rather than lowering prices, the enhanced market transparency, one economic study found, increased prices further. Compared to the control group, retail petrol prices increased by about 1.2 to 3.3 euro cents, and diesel increased by about 2 euro cents. ${ }^{29}$

${ }^{26}$ Ibid.; 'Fuel Sector Inquiry', Final Report by the Bundeskartellamt (May 2011), available at http://www.bundeskartellamt.de/SharedDocs/Publikation/EN/Sector\%20Inquiries/Fuel\%20Secto r\%20Inquiry\%20-\%20Final\%20Report.pdf? blob=publicationFile\&v=14. Together, the five companies had a combined share of approx. $64.6 \%$ of the annual fuel sales, with the remainder distributed among "a few other large oil companies and a large number of small and medium sized oil traders."

${ }^{27}$ Ibid. ("If a round of price increases is begun by Aral, Shell reacts in $90 \%$ of the cases exactly three hours later with a price increase in all of the regional markets, thereby adjusting its price level to that of Aral. Vice-versa, when Shell starts a round of price increases, in $90 \%$ of the cases Aral follows suit, again after exactly three hours. Total also generally reacts with price rises in all of the regional markets three or three-and-a-half hours after the start of the price round. Jet and Esso also react in the same way to rounds of price increases started by Aral or Shell, although the response patterns differ in some of the regional markets. Nevertheless it can be concluded that Jet often also raises its prices five hours after the start of a round of price increases, whereby it generally observes a price difference of one eurocent/litre to Aral and Shell's prices. Esso reacts between three and six hours after the start of a round of price increases. It is also apparent that on some regional markets Jet and Esso only react to rounds of price increases started in the evenings on the morning of the following day.").

28 Ralf Dewenter, Ulrich Heimeshoff, and Hendrik Lüth, 'The Impact of the Market Transparency Unit for Fuels on Gasoline Prices in Germany' (May 2016), available at http://www.dice.hhu.de/fileadmin/redaktion/Fakultaeten/Wirtschaftswissenschaftliche_Fakulta et/DICE/Discussion_Paper/220_Dewenter_Heimeshoff_Lueth.pdf.

${ }^{29}$ Ibid. 


\section{Perth, Australia}

Four major oil firms (BP, Caltex, Mobil and Shell) and two supermarket chains (Coles and Woolworths) dominated Perth's concentrated retail petrol market. ${ }^{30}$ In 2001, the government introduced a petrol price transparency program called Fuelwatch. Each firm had to submit before $2 \mathrm{pm}$ their next day's station-level prices. When stations opened the next day, they by law had to post the submitted prices. Retail prices were fixed at these posted levels for 24 hours.

Fuelwatch proved useful in promoting tacit collusion. Rivals could see on-line the prices for every petrol station in the market, and after 2:30 pm each day, tomorrow's prices. What the economic study found was that the market leader, BP, through trialand-error and experimentation, eventually facilitated tacit collusion, which "substantially improved retail margins, created price stability in the presence of aggregate shocks, and enabled firms to resolve conflict quickly.”31

Now imagine, as is the case in many states, ${ }^{32}$ a smartphone app tells you the petrol price at every local station. That may sound procompetitive. The increase in price transparency lowers your search costs. Indeed, in markets characterized by many sellers and many knowledgeable consumers, the gas app may promote competition. But also imagine if the petrol station owners shifted pricing decisions from humans to pricing algorithms. The combination of pricing algorithms and petrol apps can have the opposite effect.

30 David P. Byrne and Nicolas de Roos, 'Learning to Coordinate: A Study in Retail Gasoline' (January 19, 2017), available at SSRN: https://ssrn.com/abstract=2570637 or http://dx.doi.org/10.2139/ssrn.2570637. According to the study, "post 2010 we see a change. BP, the market leader, introduced Thursday price jumps. At first the price jumps were limited to the majority of its own stations, but soon we saw BP's competitors conform to the Thursday jumps at different rates. After only two years, Thursday jumps were solidified as a focal point for setting market prices." See David Byrne, 'How Tacit Collusion Makes Consumers Pay, Pursuit (February 13 2017), available at https://pursuit.unimelb.edu.au/articles/how-tacit-collusion-makesconsumers-pay.

31 Ibid.

32 Fuel apps have become a common feature and can be downloaded for free. 
In Perth, it took, the study's authors noted, 12 years from the start of the government's price transparency policy for the six competitors "to develop a stable collusive pricing structure." 33 With real-time pricing for each petrol station, competitors no longer have to drive past neighboring gas stations several times a day, report the pricing information to headquarters, and then react. Nor do they have to monitor the government website to identify when another station changes its prices. Rivals' pricing algorithms can observe all the competitively significant terms and promptly respond to any discount. By shifting pricing decisions to computer algorithms, competitors thereby increase transparency, reduce strategic uncertainty (when the pricing algorithm cannot grant secretive discounts), and thereby stabilize the market. ${ }^{34}$ When one petrol station lowers the price by one cent at 11:33 A.M., within milliseconds other nearby stations can respond by lowering their price.

As these case studies reflect, with each firm tapping into its rivals' real-time pricing, no petrol station likely profits by discounting. Given the velocity with which the pricing algorithms can adjust, petrol stations will less likely develop among its customers a reputation as a price discounter. Accordingly, the competitors will have even less incentive to discount. We can see that even in markets where tacit collusion should be unlikely given the number of significant competitors (such as five in Germany and six in Perth), an app that was meant to promote price competition could end up undermining it.

On the flip side, the algorithms' velocity of pricing decisions can shorten the time period for signaling price increases. Firms would no longer have to rely on lengthy (e.g., thirty-day) price announcements, where they wait and see what the competitive response is, to decide whether to raise prices (and to what extent). Computers can have multiple rounds whereby one firm increases prices and the rival computers respond immediately and without the risk that the firm that initiates the price

\footnotetext{
33 Byrne and de Roos (n 30).

${ }^{34}$ See Salil K. Mehra, 'Antitrust and the Robo-Seller: Competition in the Time of Algorithms', Minnesota Law Review 100 (March 10 2015), available at http://ssrn.com/abstract=2576341, on how pricing algorithms can promote tacit collusion under a Cournot model.
} 
increase will lose many customers to rivals. Essentially, companies may now need only seconds, rather than days, to signal price increases to foster collusion.

\section{I.iii Hub and Spoke}

The industry-wide use of pricing algorithms increases both market transparency and the risk of tacit collusion. Moreover, in programming its pricing algorithm, each firm will likely use historic pricing data and competitive responses to calibrate the dominant strategy. As such, when the algorithms operate within the greater transparency of their digitalized environment, the computers will already be programmed to anticipate and respond to rivals' moves. With the computers' ability to police deviations and rely on prior strategies to punish deviations, prices, as a result of their conscious parallelism, will likely climb not only in duopolies but in other concentrated markets.

These trends may further intensify when one considers the emergence of hub-andspoke structures.

Our focus here is not on the traditional hub-and-spoke price-fixing conspiracies, aimed at competitors' expressly fixing the price or facilitating cartel activities. Rather, we note how in an online environment a hub-and-spoke framework may emerge when sellers use the same algorithm or the same data pool to determine price.

In Virtual Competition, we noted the independent business justifications for

competitors to outsource their dynamic pricing to a third-party. The upstream provider uses its and its clients' access to industry data to train its algorithms to optimize price. Rather than incur the costs (and time) to amass the data unilaterally to train its own algorithm, rivals may find it more cost-effective to use the same thirdparty. 
An industry-wide use of a single algorithm, which competitors use to determine the market price or react to market changes, would result in de-facto hub-and-spoke structure, as the market behavior of the competitors aligns due to the use of a similar "brain" to determine their price strategy. These effects intensify when sellers use the same data pool and are privy to vast volumes of data. Hub-and spoke structures may therefore be observed at the input level (data) and the output level (algorithm).

To illustrate, let us return to the sale of petrol. Imagine how tacit collusion may be further stabilized as petrol sellers find it rational to use the same company to provide them with pricing decisions and allow that company to harvest relevant data to feed its algorithm.

Take for example a recently reported story about the market for petrol in Rotterdam, the Netherlands. According to the Wall Street Journal, petrol stations there use advanced analytics to determine petrol prices, provided by the Danish company a2i Systems. ${ }^{35}$ While the use of the same algorithm to determine price may well be legitimate, one wonders whether it may further facilitate alignment of price decisions.

The Wall Street Journal story noted how price at the relevant petrol stations dropped at times, to reflect a change in demand. It also notes how during some periods, 'the stations' price changes paralleled each other, going up or down by more than 2 U.S. cents per gallon within a few hours of each other. Often, prices dropped early in the morning and increased toward the end of the day, implying that the A.I. software may have been identifying common market-demand signals through the local noise. ${ }^{36}$

This anecdotal example supports the assertion that as competitors use a single hub - a single provider for algorithmic pricing - one may expect, in markets susceptible to tacit collusion, greater alignment of pricing decisions and higher prices overall. In

\footnotetext{
35 Sam Schechner. 'Why Do Gas Station Prices Constantly Change? Blame the Algorithm', Wall Street Journal (May 8 2017), available at https://www.wsj.com/articles/why-do-gas-station-pricesconstantly-change-blame-the-algorithm-1494262674.

36 Ibid.
} 
the context of our discussion on tacit collusion, this could evidently further stabilize the algorithmic driven equilibrium.

\section{I.iv How secret deals can pave the road to near-perfect price discrimination}

If transparency fosters tacit collusion, then secret deals should destabilize it. We are all familiar with secret deals (such as the hotel discount given 'just to you') and with targeted promotions. These may indeed provide a valuable avenue to re-introduce competition to markets susceptible to algorithmic tacit collusion. When these secret deals are carried away from the marketplace, they do not trigger a price war. They can provide a discount on the tacit equilibrium and as such benefit consumers.

Indeed, the competition agency may welcome secret discounts, product differentiation (as it introduces asymmetry among firms both in terms of cost and quantity) and reduced transparency. Ideally, a maverick firm would offer secret deals that undercut the collusive price and thereby destabilize the tacit equilibrium.

Without underestimating these potential benefits, policymakers should be mindful of two additional anticompetitive outcomes-namely, 'almost perfect behavioral discrimination' and a hybrid discrimination/collusion equilibrium which may follow.

Our concern with behavioral discrimination involves two shifts: first from thirddegree to first-degree price discrimination; and second, shifting the demand curve to the right in inducing us to buy things we ordinarily wouldn't have (or want). This is supported by the use of personal data to track consumers' behavior, and approximate the buyer' price sensitivity, awareness of outside options and willingness to pay. Increasingly, in our online environment, price is both dynamic and personalized - 
changing based on a range of parameters, such as where we live, the computer we use, our search history, our loyalty preferences etc. ${ }^{37}$

Let us return to our petrol station example where tacit collusion was facilitated. To break out from the equilibrium, a maverick could engage in secrete discounts for the benefit of consumers. However, in a data-driven economy, this strategy may evolve and result in consumer manipulation. Using the data it compiles on customers, a seller can estimate the necessary discount to induce patronage. Advances in customer profiling and novel personalized pricing strategies may enable the petrol stations to better approximate a consumer's willingness to pay - the reservation price - and charge accordingly.

The ultimate goal for each of the sellers would be to remove the buyer from the competitive environment (what is often referred to as 'acquisition' of the buyer) entice loyalty and trust - which would enable subsequent transfers of wealth from the buyer to the seller.

In our earlier work, we referred to this as the Truman Show - creating a façade of competition while profiting from the asymmetry of information and degradation of

37 At the basic level, sellers already 'personalize' price with no 'private' information - just by relying on the time and path used before making a purchase. For example, a direct log in to a seller website will often result in higher price than a referral from a price comparison website. The logic behind this simple distinction lies in the assumption as to the buyer's awareness of outside options. In essence, the net price for a product is adjusted to cater to competition conditions (dynamic pricing), the awareness of the buyer to those conditions and its reservation price (personalized discriminatory pricing). If the buyer indicates hesitation - by continuing his search or leaving goods in the checkout - this can be remedied immediately by offering surprise discounts and coupons. Framing of the price change as discounts ensures customer satisfaction. More advanced discrimination may take into account personal information, enabling the seller to create a more complex profile for the user - taking account of past behavior, preferences, communications and other data points. These could then be used to determine the order of search results and the price charged; On the power of algorithm to collect digital crumbs of data and creates a profile of the users, see: Michal Kosinski: The End of Privacy, available at: https://www.gsb.stanford.edu/insights/michal-kosinski-end-privacy 
privacy protection. The buyer - unaware of the customer profile that the seller has developed about her - assumes that the price is the market price. Given the profitability of these strategies, dynamic personalized pricing will likely increase under certain market conditions. ${ }^{38}$ In such cases, the attempt to increase welfare through secrete deals may backlash.

\section{I.v Hybrid collusion/discrimination scenario}

So far we have assumed markets with stable algorithmic tacit collusion and markets that shift between tacit collusion and behavioral discrimination. Importantly, algorithmic tacit collusion and behavioral discrimination can occur simultaneously in markets where conditions for both exist. Sellers, for example, tacitly collude for the "low value" and loyal customers and behaviorally discriminate for the "high value" customers. The seller seeks to lure the "high value" buyers with personalized discounts. Once the hook is lodged (i.e., the customer's loyalty is established and control over outside options is achieved), the seller profits by offering the cheapest individualized inducement to secure the greatest profits.

To illustrate this strategy, let us go to Las Vegas. One recent experiment involved about 1.5 million consumers who frequented MGM's Las Vegas casinos. ${ }^{39}$ Some consumers were loyalists: they would have played at the particular MGM casino even

\footnotetext{
382010 US Horizontal Merger Guidelines at 6: "[f]or price discrimination to be feasible, two conditions typically must be met: differential pricing and limited arbitrage."). Under the first condition, suppliers "must be able to price differently to targeted customers than to other customers. This may involve identification of individual customers to which different prices are offered or offering different prices to different types of customers based on observable characteristics."; "In other cases, suppliers may be unable to distinguish among different types of customers but can offer multiple products that sort customers based on their purchase decisions." Under the second condition, "the targeted customers must not be able to defeat the price increase of concern by arbitrage, e.g., by purchasing indirectly from or through other customers."

39 Harikesh S. Nair, Sanjog Misra, William J Hornbuckle IV, Ranjan Mishra, and Anand Acharya, 'Big Data and Marketing Analytics in Gaming: Combining Empirical Models and Field Experimentation', Working Papers (Faculty) -- Stanford Graduate School Of Business 1-47. Business Source Complete, EBSCOhost (accessed April 7, 2017).
} 
without a promotion. Others were "low-value" customers: they were either highly skilled "experts" who win back from the house more than they wager, consumers "who utilize comps but do not play at the resort," and consumers "who wager nothing more than their Free-play dollars, thereby gaining the upside from the promotion, with little downside for themselves and no gain for the "house."

MGM casino did not care to compete with the other casinos to attract the low-value players with promotions. Presumably the rival casinos similarly were disinterested in attracting the low-value players. Nor did each casino want to condition their loyalists with the expectation of promotions. They would come to the same casino with or without a promotion. The trick was identifying the "high value" consumers, those with the highest marginal propensity to respond to a promotion, and who would spend the greatest amount for the smallest inducement needed. The problem was that the casino's earlier promotions did not accurately distinguish the "high value" players from the "loyalists" who needed no inducements and the "low value" customers, whom it did not want to attract with any promotions. Moreover, as the study found, there was "an overarching concern that targeting more promotions to those who have played a lot in the past may be ineffective, because those consumers may already be on the flat or declining part of their promotion response curve."

The challenge for the casino's marketing team was to price optimize (what we refer to as behaviorally discriminate), namely to offer "a mix of promotions to each consumer based on what produces maximal marginal benefit at minimal cost." There were multiple dimensions to behaviorally discriminate, such as room offers (like the room type, room discount, number of comp nights, whether the comp is midweek or weekend); entertainment, sports and facility offers (including the type of amenity and 
discount); casino event information, ${ }^{40}$ other special event metrics, ${ }^{41}$ retail and spa offers, ${ }^{42}$ air and limo offers, ${ }^{43}$ free-play and promo-chip offers (like the free-play offer amount and promo-chip offer amount), resort credits, and food and beverage offers. Moreover, the challenge was not simply snagging the "high value" customer once. Rather, it was incorporating the dynamic effects of promotions on each customer "to get an accurate picture of the ROI profile from the promotions, and to allocate them appropriately based on their expected long-run benefits to the firm." Thus, the aim was to maximize profits from each marginal consumer for whom the promotion would have an incremental impact.

The means to this end were to mine the casino's voluminous personal data on the gamblers to identify whom to target, their potential value, and the best inducement to maximize the greatest profit. The casino, through its loyalty program, had a lot of data on many of its customers. So the computer model used data on each consumer's observed behavior "at all past visits (and not just the most recent visits) to measure customer value." For those consumers on whom very little data existed, the computer model pooled information from the behavior of similar consumers. The model also used "information across the entire range of activities by the consumer to measure how promotions affect behavior." Moreover, the model metrics were "both historydependent (retrospective) and forward-looking (prospective)." One example is the customer who visited the casino once, but spent little. If considering solely this past purchase, the computer might deem the customer "low value." To avoid this error, the

\footnotetext{
40 Ibid (like "inclusion in the casino event prize pool, the prize pool format, indicator for grand prize inclusion, grand prize format, prize value offered, cost of event for which offer is made, buyin amount, points to entry if offered, tier credits to entry if offered").

${ }^{41}$ Ibid ("like indicators for special event, tier upgrade offers, tier credits offered, offers of points that count toward higher tiers in the MGM loyalty program, comps linked to points, point multiplier offers, and multipliers on points that count toward higher tiers (offered on visits that overlap with birthdays)").

42 Ibid (like "indicator for a retail offer, retail offer amount, indicator for spa offer, and spa service amount").

${ }^{43}$ Ibid (like "indicator for an airline offer, air package amount, indicator for limo offer, indicator for VIP check-in flag”).
} 
computer analyzed not only the historical first-visit information on the consumer but also "the observed long-run spending of other similar consumers." Even if the customer spent little on the first visit, the model, using data from other similar gamblers, estimated if she, like these other consumers, would likely spend a lot in future visits. In processing all this data, the computer then identified the focal consumers to target, how they would likely respond to a myriad combination of promotions, and the likely profits from each consumer over the long-run under the different inducements.

The effect of the data-driven personalized promotions, the study found, was between $\$ 1$ million to $\$ 5$ million dollars of incremental profits per campaign compared to the casino's status-quo marketing strategy. Profits also increased from the improved matching of promotion types to consumer types. In sum, a dollar spent in promotions generated "about $20 \notin$ more incremental profit using the model compared to the [then] current practice at the firm."

The casino example illustrates the power of data. That power may be legitimately used for 'smart' promotions. It may also be used to engage in a hybrid tacit collusion/behavioral discrimination strategy—namely: tacitly collude on the posted price to profit from the "low-value" and loyal customers; behaviorally discriminate for the "high-value" customers.

Let us now return to our earlier example of the petrol stations. Suppose petrol stations have loyalists (those who would patronize that petrol station without any inducement), low-value customers (e.g., those who buy the cheapest, lowest grade gas, use the restroom, and rarely buy anything from the store) and high-value customers (those who are likely to purchase higher margin goods and services inside the gas station). Because of the ROI from the low-value customers, each petrol station would have little incentive to deviate from the posted price to attract them. So the baseline posted price would likely follow our algorithmic tacit collusion scenario. The "low 
value" and loyalist customers, like the Germans, Australians and Chileans customers, pay the inflated posted gas pump price.

On the second level, the petrol stations may mine the personal data to identify and attract the "high-value" customers. The aim is to steer the profitable "high value" buyers to its petrol stations through personalized advertising, discounting, bundling of services, loyalty programs and other inducements. The "high-value" buyer, through a loyalty program credit card, for example, might get a slight discount at the pump. As with the casino, the scope of the discount and promotions is determined on that customer's predicted lifecycle spending. Once some level of loyalty is established, the aim, through personalized pricing and discounts, is to maximize profitability over the lifespan of the customers' purchase history (the lottery tickets, snacks, food, drink, and merchandise they buy, and the late fees and interest payments from the gasoline credit card).

So at the acquisition stage, the petrol station's discounts, loyalty programs, coupons and other tools may appear competitive (and contrary to any tacit collusion scenario). In many ways, at this stage, the brick-and-mortar and virtual competition environment exhibit similar marketing strategies. The differences emerge in the second phase, when personalized pricing, based on mining personal data, enables the seller to customize inducements to attract that particular customer, build her loyalty, and then maximize profits from that customer (price selectively for that package of goods to match the customer's willingness to pay). The buyer is no longer anonymous. The seller, benefiting from brand recognition, loyalty and asymmetric information, can determine what is the cheapest inducement needed to reap the greatest supracompetitive profits from him. Optimization may be per deal, basket or over the customer's lifetime.

Ultimately our hybrid scenario harms everyone: the loyalists, the low-value customers and the high-value customers. In combining both tacit collusion and 
behavioral discrimination, sellers profit at each level. The pricing algorithms, in tacitly colluding over the posted petrol pump price, maximize profits from the lowvalue customers; if the ROI from personalized inducements to rivals' loyal customers is low, then the loyalists, like sleepers ${ }^{44}$, continue to pay the supra-competitive price as well. The sellers, like the MGM-owned casinos, would employ "a scalable, datadriven micro-targeting policy" to attract the high-value customers, but in the end, the objective is to secure the maximum profits from them (or, to put it more bluntly, to fleece them).

Of course, competition can break out in our hybrid scenario. For example, competitors might differ over who their low- and high-value customers are. One firm's deadbeat might be another firm's prize. But as the algorithms learn through trial-and-error and with the increasing volume and variety of personal data, they will have a better idea of the potential ROI for different inducements for each customer. Unless a lowvalue customer's behavior changes when frequenting a different casino or gas station, one would expect the algorithms to converge on who is likely to be a deadbeat. If so, we may see a prime or "base-level" market forming for the loyal sleepers and lowvalue customers, and a different, less transparent market consisting of individualized marketing efforts to lure the "high-value" customers.

A real-life illustration of a similar strategy may be found in the operation of the Danish company a2i Systems, mentioned above, whose AI algorithms powers the Rotterdam petrol stations. The software operated by a2i Systems is focused primarily on modeling consumer behavior and learns when raising prices drives away

\footnotetext{
${ }^{44}$ Some customers, for example, are known as "sleepers," who "out of indolence or ignorance don't shop around but instead are loyal to whichever seller they've been accustomed to buy from." Alex Chisholm (CMA chief executive), 'Why "Sleepers" Can't Always Be Left to "Sleep", CCRP 2016 Competition Policy Roundtable (London: Competition Markets Authority, 25 January 2016), available at https://www.gov.uk/government/speeches/alex-chisholm-on-consumer-engagementin-a-digital-world [Accessed 3 October 2016]; quoting In Re Text Messaging Antitrust Litigation 782 F.3d 867, 874 (7th Cir.) cert. denied sub nom and Aircraft Check Servs Co $v$ Verizon Wireless 136 S. Ct. 524 (2015). ísep?
} 
customers and when it doesn't. ${ }^{45}$ In a case study found on its website, the company discussed how it helped OK Benzin, Denmark's leading petrol station owner, avoid a price war: "Between 2007 and 2012 the market was characterized by fierce competition and high volatility. At the peak there were 10 to 20 price changes a day, and the spread between the highest and the lowest price of the day could be up to 15 eurocent." 46 In enlisting a2i Systems, the leading retail network of approximately 700 petrol stations (which accounted for $25 \%$ of the Danish retail fuel market), sought "to improve the pricing analysis and decision process and optimize pricing according to their overall strategy in order to lower the cost of price wars or better yet, to avoid them." 47

In discussing generally about its pricing algorithms, the Chief Executive of a2i Systems noted that ' $[\mathrm{t}]$ his is not a matter of stealing more money from your customer. It's about making margin on people who don't care, and giving away margin to people who do care.' 48 As the Wall Street Journal reported, the complex algorithm operated by a2i Systems was tested against a control group which did not use the system to determine price. The result? 'The group using the software averaged 5\% higher margins. ${ }^{49}$ For the petrol company, a2i Systems notes, "means millions of Euros" more annually. 50

\footnotetext{
45 Schechner (n 35). See also the company website: "PriceCast Fuel utilizes Artificial Intelligence (AI) to optimally reach the local and/or global target for any given station and product. By continuously monitoring data (such as transactions, competitors' prices, time, location, traffic, weather, etc.) PriceCast Fuel learns about customers' and competitors' behaviors and optimizes the price for each product at each site, taking every significant correlation into account." Available at http://a2isystems.com/pricecast.html\#pricecast-fuel-19.

46 PriceCast $\quad$ Fuel Case Story, available at http://a2isystems.com/files/pdf/PriceCast\%20Fuel\%20Case\%20Story\%20('15).pdf.

47 Ibid.

48 Ibid.

49 Ibid.

50 Ibid.
} 


\section{I.vi Scaremongers and science fiction}

The above discussion illustrates the application of current technologies to online markets. Importantly, it is neither based on futuristic prediction nor vague assumptions. It simply describes the current state of technology.

One ought to carefully consider these strategies and their likely welfare effects. Should one accept these strategies as part of natural market development? Or, should we introduce checks and balances to more closely scrutinize new market strategies? Importantly, whichever view one takes on the significance of these present strategies, all would agree that any enforcement agenda should be carefully measured and mindful of the risk of over- and under-intervention.

Interestingly, despite these strategies already being present in some markets, some interested tech companies invest heavily in reframing the debate. They portray the concerns as futuristic - an interesting speculative discussion. Further, they argue that the technology is so complex, the industry is so dynamic, and entry barriers are so low, that antitrust enforcers need not be concerned. In increasing numbers of events, one hears their lawyers, lobbyists, and sponsored academics encourage enforcers to keep calm and, preferably, sleep tight. After all, technology is far too complex for competition officials to comprehend, the risk of false positives are too great, and markets will quickly correct themselves.

Needless to say, one should indeed remain calm. Indeed, as the next Part explores, most policymakers, enforcers, and regulators publicly acknowledge the current changes and are critically assessing how these changes in market dynamics may require updating or modifying their enforcement tools. They do not necessarily call for intervention, but the consensus is that the agencies must at least accept the actual (or potential) change in market dynamics and be ready to critically consider the adequacy of current enforcement tools to address algorithmic collusion. There is also 
a general consensus that tacit collusion, whether algorithmic or otherwise, harms consumers and that, while merger control may be used to address future risk of tacit collusion, other enforcement tools cannot directly stop it.

Most policymakers recognize how 'pricing algorithms may make price fixing attempts more frequent and potentially more difficult to detect.'51 Most say 'with confidence ... that the rise of pricing algorithms and AI software will require changes in our enforcement practices;' and most would agree that enforcers 'need to understand how algorithms and AI software work in particular markets. ${ }^{52}$

On the other hand, some competition enforcers believe that algorithmic collusion is nothing new. ${ }^{53}$ This divide highlights the two core questions at the heart of our discussion: First, should the use of algorithms in some instances, in a way that does not offend current competition laws, lead to an introduction of a new category of violations? Second, does the competition agency have the tools to confront such new violations?

The acting FTC Chair recently characterized the discussion of algorithmic collusion as 'a bit alarmist.'54 She noted that '[u]nilateral efforts to understand market conditions better and respond to them are a critical part of a well-functioning economy.' She added: 'Nor do I think that the Federal Trade Commission is planning to take away your ability to use mathematics and computers to fully engage with

51 Terrell McSweeny, Commissioner, U.S. Federal Trade Commission, 'Algorithms and Coordinated Effects', University of Oxford Center for Competition Law and Policy (May 22, 2017), available at https://www.ftc.gov/system/files/documents/public statements/1220673/mcsweeny _oxford_cclp_remarks_-algorithms_and_coordinated_effects_5-22-17.pdf.

52 Ibid.

${ }^{53}$ Leah Nylen and Matthew Newman, 'Views on Algorithms and Competition Law Expose EUUS divide', MLex (May 26 2017).

${ }_{54}$ Maureen K. Ohlhausen, Acting Chairman, U.S. Federal Trade Commission, 'Should We Fear the Things That Go Beep in the Night? Some Initial Thoughts on the Intersection of Antitrust Law and Algorithmic Pricing' (May 23 2017). 
markets as effectively as you can.' On the technology involved and the ability to scrutinize it, she noted that: ' $[\mathrm{t}]$ he inner workings of these tools are poorly understood by virtually everyone outside the narrow circle of technical experts that directly work in the field.' 55

Reflecting on her comments, we would like to stress the following points. First, we note that the strategies discussed in this Part are not futuristic; firms are increasingly using pricing algorithms, some to increase profits and avoid price wars. Second, while tacit collusion in some brick-and-mortar markets might have frequently failed or broken down, in other markets the speed and transparency of algorithms can make tacit collusion more durable. Third, her position is understandable if the U.S. economy were robustly competitive, and thus even with algorithms, only a few markets, if that, would be susceptible to tacit collusionalgorithmic or otherwise. But with the growing evidence of increased concentration, profits flowing into fewer hands in the U.S., slowdown in startups and worker mobility, and growing wealth inequality, her statements are curious, especially if the growing levels of concentration may make more markets susceptible to algorithmic collusion. Finally, we note how, to date, most strategies discussed are powered by price algorithms and are yet to include cutting-edge neural networks. The increased use of neural networks will indeed complicate enforcement efforts. But even then, one should not accept this black-box argument as a justification for apathy; the agencies must critically review how these algorithms are affecting affect market dynamics.

We further explore these themes, the question of legality and enforcement, in Part II;

55 Ibid. 


\section{Part II \\ Enforcement challenges}

Having explored the interlinked strategies - algorithmic tacit collusion, hub-andspoke, behavioural discrimination, we now consider the enforcement challenges they raise.

Several policymakers over the past two years have acknowledged algorithmic collusion as a possible antitrust concern. ${ }^{56}$ The European Commission, noted that, among other things, 'increased price transparency through price monitoring software may facilitate or strengthen (both tacit and explicit) collusion between retailers by making the detection of deviations from the collusive agreement easier and more immediate. This, in turn, could reduce the incentive of retailers to deviate from the collusive price by limiting the expected gains from such deviation.'57

The French and German competition authorities similarly noted in a joint report that:

\footnotetext{
56 In its 2016 Preliminary Report on the E-commerce Sector Inquiry, the European Commission noted the rise in use of monitoring algorithms: "About half of the retailers track online prices of competitors. In addition to easily accessible online searches and price comparison tools, both retailers and manufacturers report about the use of specific price monitoring software, often referred to as "spiders", created either by third party software specialists or by the companies themselves. This software crawls the internet and gathers large amounts of price related information. $67 \%$ of those retailers that track online prices use (also) automatic software programmes for that purpose. Larger companies have a tendency to track online prices of competing retailers more than smaller ones... some software allows companies to monitor several hundred online shops extremely rapidly, if not in real time... Alert functionalities in price monitoring software allow companies to get alerted as soon as a retailer's price is not in line with a predefined price." Brussels, 15.9.2016 SWD(2016) 312, paras 550-551, available at http://ec.europa.eu/competition/antitrust/sector_inquiry_preliminary_report_en.pdf 57 'Commission Staff Working Document accompanying Commission Final report on the Ecommerce Sector Inquiry' (May 10 2017) COM(2017) 229 final, para 608. Also note the European Commission investigations into online sales practices launched on 2 February 2017. As part of the investigation into Consumer electronics manufacturers, the Commission will also consider the effects of pricing software that automatically adapts retail prices to those of leading competitors.
} 
Even though market transparency as a facilitating factor for collusion has been debated for several decades now, it gains new relevance due to technical developments such as sophisticated computer algorithms. For example, by processing all available information and thus monitoring and analysing or anticipating their competitors' responses to current and future prices, competitors may easier be able to find a sustainable supra-competitive price equilibrium which they can agree on. ${ }^{58}$

Likewise, the U.K. House of Lords noted how the rapid developments in data collection and data analytics have created the potential for new welfare reducing and anti-competitive behaviour, including new forms of collusion. ${ }^{59}$ And the OECD in 2016 commented that these strategies "may pose serious challenges to competition authorities in the future, as it may be very difficult, if not impossible, to prove an intention to coordinate prices, at least using current antitrust tools." 60

We divide the discussion of the key enforcement challenges posed by algorithmic tacit collusion, under three main headings: Liability, Detection, and AI Law and Policy.

\section{II.i Liability}

Algorithmic tacit collusion raises challenging questions with respect to liability. Even if the agency detects algorithmic tacit collusion, what can they do about it? Under most jurisdictions' antitrust laws, the unilateral use of algorithms to monitor and set

\footnotetext{
58 Competition Law and Data (May 10 2016) at 14, with reference to our earlier work ('Artificial intelligence and collusion: when computers inhibit competition'), available at http://www.bundeskartellamt.de/SharedDocs/Publikation/DE/Berichte/Big\%20Data\%20Papier.p df? blob=publicationFile\&v $=$.

59 European Union Committee on Online Platforms and the Digital Single Market, 10th Report of Session 2015-16, paras 178-179, available at https://www.publications.parliament.uk/pa/ld201516/ldselect/ldeucom/129/12908.htm.

60 'Big Data: Bringing Competition Policy To The Digital Era', DAF/COMP (2016) 14 October 27 2016, at para 84, available at https://one.oecd.org/document/DAF/COMP(2016)14/en/pdf.
} 
price is legal, even if it leads to prices above competitive levels. ${ }^{61}$ After all, one cannot condemn a firm for behaving rationally and interdependently on the market. ${ }^{62}$

When the algorithms increase market transparency, defendants will often have an independent legitimate business rationale for their conduct. Courts and the enforcement agencies may be reluctant to restrict this free flow of information in the marketplace. Its dissemination, observed the U.S. Supreme Court, "is normally an aid to commerce,"63 and "can in certain circumstances increase economic efficiency and render markets more, rather than less, competitive."64 Indeed, concerted action to reduce price transparency may itself be an antitrust violation. ${ }^{65}$

Accordingly, 'pure' forms of tacit collusion which result from a unilateral rational reaction to market characteristics would not normally trigger antitrust liability. On the other hand, intervention may be triggered when an illicit concerted practice

${ }^{61}$ Rational unilateral reaction to market dynamics (free from agreements or communications) in itself, is legal under EU and US competition law, As noted earlier, tacit collusion does not amount to concerted practice and therefore escapes Article 101 TFEU. Tacit collusion may serve to establish Collective Dominance under Article 102 TFEU, but absent a separate abuse, it will also escape scrutiny under this provision.

62 See, for example, Case C-199/92, P Hüls AG v. Commission, [1999] ECR I-4287, [1999] 5 CMLR 1016; Joined Cases C-89, 104, 114, 116, 117, 125, 129/85, Ahlström Osakeyhtiö and others v. Commission (Wood Pulp II), [1993] ECR I-1307, [1993] 4 CMLR 407; Cases T-442/08, CISAC v Commission, [2013] 5 CMLR 15 (General Court).

63 Sugar Institute, Inc. v. United States, 297 U.S. 553, 598 (1936).

64 United States v. United States Gypsum Co., 438 U.S. 422, 441 n.16 (1978); See also Richard A. Posner, Antitrust Law, 2nd ed. (Chicago: University of Chicago Press, 2001), 160. Generally, the more information sellers have about their competitors' prices and output, the more efficiently the market will operate.

65 See, for example, 'Federal Trade Commission, Funeral Directors Board Settles with FTC' (August 16, 2004), http://www.ftc.gov/opa/2004/08/vafuneral.htm (a board's prohibition on licensed funeral directors advertising discounts deprived consumers of truthful information); Federal Trade Commission, Arizona Automobile Dealers Association, FTC C-3497 (February 25, 1994) (a trade association illegally agreed with members to restrict nondeceptive comparative and discount advertising and advertisements concerning the terms and availability of consumer credit); Organisation for Economic Co-operation and Development, Price Transparency, DAFFE/CLP(2001)22 (September 11, 2001), 183, 185-186 (citing examples of U.S. enforcement agencies seeking to increase price transparency); compare InterVest, Inc. v. Bloomberg, L.P., 340 F.3d 144 (3d Cir. 2003) (lack of price transparency in bond market not illegal if consistent with unilateral conduct). 
'contaminated' or 'facilitated' the conscious parallelism. In some instances, the unilateral nature of the action may be questioned. At times, either a horizontal or vertical agreement may be inferred. Condemned actions may include signaling, exchange of information, agreement to engage in common strategy, manipulation through the sharing of data pools and other collusive strategies.

Illustrative is the EU Commission's recent investigation into suspected anticompetitive practices in e-commerce. In February 2017, the Commission announced an investigation into possible breaches of EU competition law by Asus, Denon \& Marantz, Philips and Pioneer. Among other things, the Commission is appraising whether the companies restricted the "ability of online retailers to set their own prices for widely used consumer electronics products such as household appliances, notebooks and hi-fi products." According to the Commission, "The effect of these suspected price restrictions may be aggravated due to the use by many online retailers of pricing software that automatically adapts retail prices to those of leading competitors. As a result, the alleged behaviour may have had a broader impact on overall online prices for the respective consumer electronics products." 66

Evidently, antitrust intervention is easier when algorithms are part of a wider collusive agreement to tamper with market prices. ${ }^{67}$ Similarly, weaker forms of signaling, aimed at coordinating practice of the market could be condemned.

But, the challenging question remains: should 'pure' forms of conscious parallelism be condemned? Ought we condemn the facilitation of tacit collusion through artificial means? Should one condemn a firm for behaving rationally and developing,

\footnotetext{
66 'Antitrust: Commission opens three investigations into suspected anticompetitive practices in e-commerce', European Commission (2 February 2017), available at http://europa.eu/rapid/pressrelease_IP-17-201_en.htm.

67 See for example: Topkins, available at https://www.justice.gov/opa/pr/former-e-commerceexecutive-charged-price-fixing-antitrust-divisions-first-online-marketplace.
} 
unilaterally, an algorithm that accounts publically available information while operating interdependently on the market?68

One way to square this circle may be framing the issue as market manipulation or an unfair practice. The focus shifts from the presence of an agreement among companies to the use of advanced algorithms to transform pre-existing market conditions in such a way to facilitate tacit collusion. While the mutual price monitoring at the heart of tacit collusion is legal under competition law, one may ask whether the creation of such a market dynamic, through "artificial" means, gives rise to antitrust intervention.

Using such an approach, one could consider application of legislation such as Section 5 of the FTC Act, which targets unfair facilitating practices. ${ }^{69}$ Noteworthy is how the US courts set a rather high level of intervention. Under the legal standard applied in $E t h y l^{70}$, the FTC must show either (1) evidence that defendants tacitly or expressly agreed to use pricing algorithms to avoid competition, or (2) oppressiveness, such as (a) evidence of defendants' anticompetitive intent or purpose or (b) the absence of an independent legitimate business reason for the defendants' conduct. ${ }^{71}$ Accordingly, defendants may be liable if, when developing the algorithms or in seeing the effects, they were (1) motivated to achieve an anticompetitive outcome, or (2) aware of their actions' natural and probable anticompetitive consequences.

An alternative route may target "abuse" of excessive transparency, possibly where clear anticompetitive intent is present. One could employ the rationale

\footnotetext{
68 See, for example, Case C-199/92, P Hüls AG v. Commission, [1999] ECR I-4287, [1999] 5 CMLR 1016; Joined Cases C-89, 104, 114, 116, 117, 125, 129/85, Ahlström Osakeyhtiö and others v. Commission (Wood Pulp II), [1993] ECR I-1307, [1993] 4 CMLR 407; Cases T-442/08, CISAC v Commission, [2013] 5 CMLR 15 (General Court).

69 The FTC was unsuccessful in its attempt to prove such facilitating practices in Boise Cascade Corp. v. F.T.C., 637 F.2d 573 (9th Cir. 1980) and E. I. du Pont de Nemours \& Co. v. F.T.C., 729 F.2d 128 (2d Cir. 1984).

70 E. I. du Pont de Nemours \& Co. v. F.T.C., 729 F.2d 128 (2d Cir. 1984).

71 Ibid, 128, 139.
} 
used in the U.S. Securities and Exchange Commission's (SEC) case against Athena Capital Research. ${ }^{72}$ In 2014, the SEC for the first time sanctioned the high-frequency trading firm for using complex computer programs to manipulate stock prices. ${ }^{73}$ The sophisticated algorithm, code-named Gravy, engaged in a practice known as "marking the close" in which stocks were bought or sold near the close of trading to affect the closing price: "[t]he massive volumes of Athena's last-second trades allowed Athena to overwhelm the market's available liquidity and artificially push the market priceand therefore the closing price-in Athena's favor."74 Athena's employees, the SEC alleged, were "acutely aware of the price impact of its algorithmic trading, calling it 'owning the game' in internal e-mails." 75 Athena employees "knew and expected that Gravy impacted the price of shares it traded, and at times Athena monitored the extent to which it did. For example, in August 2008, Athena employees compiled a spreadsheet containing information on the price movements caused by an early

72 Ibid. U.S. Securities and Exchange Commission, Administrative Proceeding File No. 3-16199 (October 16, 2014), http://www.sec.gov/litigation/admin/2014/34-73369.pdf.

73 The computer trading program was "placing a large number of aggressive, rapid-fire trades in the final two seconds of almost every trading day during a six-month period to manipulate the closing prices of thousands of NASDAQ-listed stocks." U.S. Securities and Exchange Commission, SEC Charges New York-Based High Frequency Trading Firm with Fraudulent Trading to Manipulate Closing Prices, October 16, 2014, available at http://www.sec.gov/News/PressRelease/Detail/PressRelease/1370543184457\#.VEOZlfldV8E.

74 Ibid.

75 Ibid. As the SEC alleged Athena's manipulative scheme focused on trading in order to create imbalances in securities at the close of the trading day: "Imbalances occur when there are more orders to buy shares than to sell shares (or vice versa) at the close for any given stock. Every day at the close of trading, NASDAQ runs a closing auction to fill all on-close orders at the best price, one that is not too distant from the price of the stock just before the close. Athena placed orders to fill imbalances in securities at the close of trading, and then traded or 'accumulated' shares on the continuous market on the opposite side of its order." According to the SEC's order, Athena's algorithmic strategies became increasingly focused on ensuring that the firm was the dominant firm-and sometimes the only one - trading desirable stock imbalances at the end of each trading day. The firm implemented additional algorithms known as "Collars" to ensure that Athena's orders received priority over other orders when trading imbalances. These eventually resulted in Athena's imbalance-on-close orders being at least partially filled more than 98 percent of the time. Athena's ability to predict that its orders would get filled on almost every imbalance order allowed the firm to unleash its manipulative Gravy algorithm to trade tens of thousands of shares right before the close of trading. As a result, these shares traded at artificial prices that NASDAQ then used to set the closing prices for on-close orders as part of its closing auction. Athena's highfrequency trading scheme enabled its orders to be executed at more favorable prices. 
version of Gravy."76 Athena configured its algorithm Gravy "so that it would have a price impact."77 In calling its market-manipulation algorithm Gravy, and by exchanging a string of incriminating e-mails, the company did not help its case. Without admitting guilt, Athena paid a $\$ 1$ million penalty. This demonstrates that automated trading has the potential to increase market transparency and efficiency, but it can also lead to market manipulation. ${ }^{78}$ Finding the predominant purpose for using an algorithm will not always be straightforward. Athena, for example, challenged the SEC's allegations that it engaged in fraudulent activity: "While Athena does not deny the Commission's charges, Athena believes that its trading activity helped satisfy market demand for liquidity during a period of unprecedented demand for such liquidity."79 A court might agree. Companies, learning from Athena, can be more circumspect in their e-mails. ${ }^{80}$

Another possible intervention path, of a more general nature, may involve the use of market or sector investigations. Such approach may prove useful in helping agencies understand the new dynamics in algorithm-driven markets and the magnitude of any competitive problems. In some jurisdictions, like the United Kingdom, market investigation laws also provide for a wide scope of behavioral and structural remedies. ${ }^{81}$ Following an investigation the agency may benefit from a flexible tool box that is unavailable through other means.

76 U.S. Securities and Exchange Commission, Administrative Proceeding File No. 3-16199, para. 34 .

77 Ibid, para. 36.

78 Peter J. Henning, 'Why High-Frequency Trading Is so Hard to Regulate', New York Times (October 20, 2014), available at http://dealbook.nytimes.com/2014/10/20/why-high-frequencytrading-is-so-hard-to-regulate/.

79 Steve Goldstein, 'High-Frequency Trading Firm Fined for Wave of Last-Minute Trades', Market Watch (October 16 2014), available at http://www.marketwatch.com/story/high-frequencytrading-firm-fined-for-wave-of-last-minute-trades-2014-10-16.

80 Moreover, evidence of intent will likely be mixed when each firm has valid independent business reasons to develop and implement a pricing algorithm. After all, the first firm to use the pricing algorithm could not be accused of colluding, as the market was likelier less transparent, and rivals could not match the speed of the first mover's price changes.

81 The U.K. Competition and Markets Authority, for example, can initiate market investigations, gather and appraise evidence, and, where necessary, impose structural or behavioral remedies; Competition Commission, Guidelines for Market Investigations: Their Role, Procedures, 


\section{II.ii Detection}

Assuming that the illegality of algorithmic tacit collusion is given, one subsequently faces the challenge of detection.

Before you prosecute a crook, you must first detect the crime. That is easy with bank robbery, but not with tacit collusion. One interesting consequence of algorithm-driven tacit collusion is the difficulty in identifying the counterfactuals - in other words, the competitive position absent the industry-wide use of pricing algorithms.

In practice, it may be difficult for an enforcer or regulator to conclude whether a market dynamic forms a 'natural' outcome or was 'artificially' enhanced or created. In a market dominated by algorithms, absent a natural experiment or counterfactual (such as a similar market without algorithms), enforcers may not readily discern whether the market price is the result of artificial intervention or natural dynamics: the dynamic price may be the only market price.

One answer may involve auditing the algorithm. Under an auditing regime, the agency will assess whether an algorithm was designed to foster a change in the market dynamics. This approach resembles pre-merger review - where the agency predicts whether the proposed merger may substantially lessen competition. Accordingly, algorithms could be activated in a 'sand box' where their effects will be observed and assessed.

Auditing at times can predict anticompetitive outcomes, but it has its share of problems. Based on our discussions with computer scientists, it is not as simple as

Assessment and Remedies, CC3 (Revised) (April 2013), available at https://www.gov.uk/government/uploads/system/uploads/attachment_data/file/284390/cc3_revise

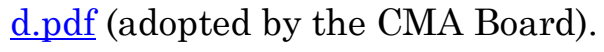


opening the hood of the car to see what's causing the irregularity. To begin with, it may be hard to establish whether the algorithm submitted for audit is the one used in the marketplace. This isn't simply a bait-and-switch by the firms. Rather, through machine-learning, trial-and-error, and market changes, the algorithm itself evolves. Similarly, the ease with which audited algorithm may be amended and set different optimization goals could undermine effective scrutiny. Other challenges include the sheer number of algorithms which would require scrutiny, the high level of expertise required to assess their effects, the ability to identify credible counterfactuals, and barriers associated with commercial secrecy. Lastly, in the case of neural networks, it may be impossible to effectively audit a complex system and determine its likely effects.

Some challenges may be addressed by shifting the burden to the companies and imposing on them a duty to comply with a set of guidelines and principles of compliance by design. One could imagine the creation of an industry code of practice, which companies must follow when designing the algorithms. Random inspections perhaps could increase deterrence and compliance.

Yet, even if one shifts the burden to companies and assumes clear benchmarks for intervention - technology may undermine the effectiveness of intervention. Already we witness the use of advanced, more complex algorithms which, as a result are more difficult to audit. This trend will likely intensify as more data can be analyzed, and changing market dynamics can be addressed, through the use of Artificial Intelligence (AI).

Of relevance are recent developments in Artificial Neural Networks, also known as 'Deep Learning', which aim to mimic the brain's cognitive and computation mechanisms. These complex networks consist of a large number of computation units 
(neurons), interconnected across several layers. ${ }^{82}$ They have already contributed to significant advances in solving some of the harder, longstanding challenges for the AI community thus far. By 2017, they have matched or surpassed human performance in a variety of tasks, such as identifying malignant tumors in breast cancer images, image labeling, speech recognition and language translation. ${ }^{83}$ Their rapid self-improvement has already resulted in instances in which they evolved beyond recognized human-like decision-making. ${ }^{84}$

An AI program, that its developers at Carnegie-Mellon University called "Libratus," recently defeated several top poker players. This achievement becomes even more impressive when considering the following: First none of Libratus's algorithms were specific to poker. As one of developers told the press, "We did not program it to play poker. We programmed it to learn any imperfect-information game, and fed it the rules of No-Limit Texas Hold'em as a way to evaluate its performance." 85 The AI program learned the optimal strategy. Second, Libratus playing style was unlike a human's. The human players could not always identify the computer's dominant strategy. What seemed like bad moves by the computer actually turned out to be good

82 Ittoo, Nguyen and van den Bosch. 'Text analytics in industry: Challenges, desiderata and trends', Computers in Industry, vol. 78, 2016, available at http://www.sciencedirect.com/science/article/pii/S0166361515300646_or http://dx.doi.org/10.1016/j.compind.2015.12.001.

${ }^{83}$ Yun Liu et al., 'Detecting Cancer Metastases on Gigapixel Pathology Images', available at https://drive.google.com/file/d/0B1T58bZ5vYa-Q1R0Q1JTa2dPWVk/view (in identifying for breast cancer patients whether the cancer has metastasized away from the breast, a trained algorithm could review large expanses of biological tissues, and automatically detect and localize tumors as small as $100 \times 100$ pixels in gigapixel microscopy images sized 100, 000×100, 000 pixels, with a rate of 8 false positives per image, and detecting $92.4 \%$ of the tumors, relative to $82.7 \%$ by the previous best automated approach, and a 73.2\% sensitivity for human pathologists); Le Cun, Bengio and Hinton, 'Deep Learning - Review', Nature, vol. 521, 2015, available at http://www.nature.com/nature/journal/v521/n7553/pdf/nature14539.pdf http://dx.doi.org/10.1038/nature14539.

84 Note for example the way in which computerized investment decision has outperformed humans. See: Gregory Zuckerman and Bradley Hope, 'The Quants Run Wall Street Now' Wall Street Journal (26 May 2017), available at https://www.wsj.com/articles/the-quants-run-wallstreet-now-1495389108.

85 Charlie Wood, 'Bot makes poker pros fold: What's next for artificial intelligence?', The Christian Science Monitor (February 4 2017), available at http://www.csmonitor.com/Technology/2017/0204/Bot-makes-poker-pros-fold-What-s-next-forartificial-intelligence. 
moves. ${ }^{86}$ And the computer's strategies seemingly varied hand-by-hand. Third, the computer's strategies evolved day-by-day. When the humans found weaknesses in the computer's play, the players could not quickly exploit these weaknesses. The computer already prioritized identifying and correcting these holes. ${ }^{87}$ After twenty days of playing poker, Libratus won decisively.

Another example involves Google's AlphaGo algorithm, which defeated in 2017 the world's best Go player. Humans have played Go, which is noted for its myriad possible moves, for centuries. Noteworthy wasn't that the best player was defeated. Rather, Go players have praised the algorithm's ability "to make unorthodox moves and challenge assumptions core to a game." 88 The world's best player, after being defeated, noted that "Last year, it was still quite humanlike when it played, but this year, it became like a god of Go." 89

Let us now consider the possible application of the technology to online markets.

Deep Learning techniques are now powering many of the applications that we use on a daily basis. These include voice recognition systems (on our mobile phones), and facial recognition systems (used by Facebook). Deep Learning has also shown much promise in directing self-driving cars.

The technology is often used in conjunction with another paradigm, known as Reinforcement Learning, which prescribes how agents should act in an environment in order to maximize future cumulative reward. The combination of Deep Learning and Reinforcement Learning is promising. It heralds the emergence of algorithms "ingrained" with advanced human cognitive abilities, such as playing Atari

86 'How AI beat the best poker players in the world' Engadget R+D (February 10 2017), available at https://www.youtube.com/watch?v=jLXPGwJNLHk.

87 Ibid.

88 Paul Mozur, 'Google's AlphaGo Defeats Chinese Go Master in Win for A.I.', The New York Times (May 23 2017).

89 Ibid. 
videogames and more importantly, beating the human champion at the GO game, considered as one of the AI holy grails. 90

Due to their complex nature and evolving abilities when trained with additional data, auditing these networks may prove futile. The knowledge acquired by a Deep Learning network is diffused across its large number of neurons and their interconnections, analogous to how memory is encoded in the human brain. These networks, based on non-linear transformations, are considered as opaque, black boxes. ${ }^{91}$ Enforcers may lack the ability to trace back the steps taken by algorithms and unravel the self-learning processes. If deciphering the decision making of a deep learning network proves difficult, then identifying an anticompetitive purpose may be impossible.

\section{II.iii AI Law and Policy}

Antitrust law is not fixed. With new harms come new laws to prevent that harm. This brings us to the issue with which policymakers are now grappling - not only for algorithmic collusion but driverless cars and other AI technology: to what extent should humans be liable for the actions of the algorithm?

In a simple scenario using today's technology, one could envisage the human operator embedding the tacit collusion model into the algorithm. Although there is no anticompetitive "agreement" among rivals, the human involvement, if one opt to condemn that action, may be relatively easy to detect. But, as noted above, the future heralds more advanced technologies that will be able to act independently, with no

\footnotetext{
90 Dharshan Kumaran and Demis Hassabis, 'From Pixels to Actions: Human-level control through Deep Reinforcement Learning', Google Research Blog (February 25 2015), available at https://research.googleblog.com/2015/02/from-pixels-to-actions-human-level.html. 91 Castelvecchi, 'Can we open the black box of AI?', Nature, vol. 538, 2016, available at http://www.nature.com/news/can-we-open-the-black-box-of-ai-1.20731 or http://dx.doi.org/10.1038/538020a; for the broader implications, see Frank Pasquale, 'The Black Box Society: The Secret Algorithms That Control Money and Information' (Harvard University Press 2015).
} 
human input. The algorithm isn't programmed to tacitly collude. Programmed with basic game theory, the algorithm like the one that defeated the world's best poker players, will identify the dominant strategy on its own to maximize profits.

A recent experiment - conducted in Google's advanced Deep Mind neural network — set to identify the dominant strategy that Deep Mind will deploy. ${ }^{92}$ Interestingly, in an environment with limited resources, Deep Mind deployed aggressive strategies in an effort to win the competition. However, when collaboration was deemed more profitable (Wolfpace game) two neural agents learned from experimenting in the environment and collaborated to improve their joint position. It will be interesting, as the literature and technology evolve, to see whether the Wolfpace scenario foreshadows the algorithmic tacit collusion scenarios where computers on their own migrate to conscious parallelism as their dominant strategy.

If so, can companies be blamed if their smart algorithms subsequently and independently identify the benefits of interdependence under the tacit collusion scenarios? Suppose, unlike the developers of Gravy, the company did not program its algorithm to manipulate the market. Nonetheless as the market dynamics evolve, the algorithms learn that the dominant rational strategy is tacit collusion. To what extent can the company be liable for the action of self-learning machine? And what checks and balances could one impose to prevent machines from changing market dynamics?

The European Commission, among others, is currently grappling with these issues. It noted how more autonomous decision-making may "conflict with the current regulatory framework which was designed in the context of a more predictable, more manageable and controllable technology." 93 It recommended clarifying and, if

92 Joel Z. Leibo et al, 'Multi-agent Reinforcement Learning in Sequential Social Dilemmas' https://storage.googleapis.com/deepmind-media/papers/multi-agent-rl-in-ssd.pdf; Also see short interview with Joel Z Leibo, the lead author on the paper at http://www.wired.co.uk/article/artificial-intelligence-social-impact-deepmind.

93 European Commission, 'Commission Staff Working Document on the free flow of data and emerging issues of the European data economy Brussels', 10.1.2017 SWD(2017) 2 final, at 43. 
necessary, adapting the legislative framework. ${ }^{94}$ Among the legal approaches under consideration are:

- a strict liability regime;

- a liability regime based on a risk-generating approach (whereby "liability would be assigned to the actors generating a major risk for others and benefitting from the relevant device, product or service"), and

- a risk-management approach (whereby "liability is assigned to the market actor which is best placed to minimize or avoid the realisation of the risk or to amortize the costs in relation to those risks").95

One significant obstacle with a risk-based approach for algorithmic tacit collusion is our ability to understand the magnitude and likelihood of risk and the actuality of harm. When a self-driving car hits a human, the harm is clear. But as discussed above for decades, antitrust enforcers (even with an attractive leniency policy) have had a hard time detecting express collusion. Detecting tacit collusion is often more difficult (especially when interdependence can appear in competitive markets). Like the human players against Libratus or AlphaGo, divining the strategy of a pricing algorithm may prove even more difficult.

As EU Commissioner Vestager noted, “[t]he trouble is, it's not easy to know exactly how those algorithms work. How they've decided what to show us, and what to hide. And yet the decisions they make affect us all." ${ }^{6}$ Significant is the ability of Deep Learning to adjust to changing environment and engage in cognitively intensive tasks. As such they form a superior tool to determine market strategy in a changing

\footnotetext{
94 Ibid.

95 Ibid. at 45 . As a complement to the above, the Commission also is entertaining voluntary or mandatory insurance schemes for compensating the parties who suffered the damage.

96 'Algorithms and competition', Bundeskartellamt 18th Conference on Competition, Berlin (16 March 2017), available at https://ec.europa.eu/commission/commissioners/20142019/vestager/announcements/bundeskartellamt-18th-conference-competition-berlin-16-march2017 en.
} 
environment. ${ }^{97}$ Indeed, some studies have already highlighted the potential of simpler, basic ANN for dynamic pricing. ${ }^{98}$ Another noteworthy characteristic is their ability to learn from experience. ${ }^{99}$ This alleviates the need for prior "hand-crafted" knowledge fed in by human in order to learn a perceptual representation of the world. The self-learning nature enables them to untangle underlying factors in data and to adjust their learning process so that they progressively improve their performance until achieving the desired outcome. ${ }^{100}$ For instance, AlphaGo, Google's Deep Learning-based GO champion, and Libratus learned to discover new strategies.

Vestager commented on this challenge and opined that 'Competition enforcers need to be suspicious of everyone who uses an automated system for pricing' and that 'businesses ... need to know that when they decide to use an automated system, they will be held responsible for what it does, so they had better know how that system works.' ${ }^{101}$ On a positive note, Vestager's comments make clear that autonomous machines can play a greater role in our markets and lives and some accountability (or compensatory) measure must exist to promote an inclusive economy. The challenge is in adapting the legislative framework so that citizens can trust and benefit from this technology while enabling the industry to "lead and capture the opportunities arising in this field." 102

\footnotetext{
${ }^{97}$ Leslie Smith, 'An Introduction to Neural Networks', University of Stirling Centre for Cognitive and Computational Neuroscience (25 October 1996), available at http://www.cs.stir.ac.uk/ lss/NNIntro/InvSlides.html.

98 Ghose and Tran, 'A dynamic pricing approach in e-commerce based on multiple purchase attributes', in Proceedings of the 23rd Canadian conference on Advances in Artificial Intelligence, Lecture Notes in Computer Science, vol. 6085, 2010, available at https://link.springer.com/chapter/10.1007/978-3-642-13059-5_13.

${ }_{99}$,Smith (n 98).

100 Castelvecchi, 'Can we open the black box of AI?', Nature, vol. 538, 2016, available at http://www.nature.com/news/can-we-open-the-black-box-of-ai-1.20731 http://dx.doi.org/10.1038/538020a.

${ }^{101}$ Lewis Crofts and Matthew Newman, 'Vestager warns of pricing algorithms' antitrust impact', MLex (16 March 2017) reporting on the Commissioner's speech at the Bundeskartellamt IKK Conference.

102 European Commission (n 94), 43.
} 


\section{Part III \\ Counter-measures}

Rather than legally challenge algorithmic tacit collusion, policymakers or consumer organizations may attempt to actively destabilize it. Such approach would seek to change the market dynamics so to undermine possible conscious parallelism, while avoiding the possible pitfalls presented by almost perfect price discrimination. Change of market dynamics may be achieved by using the same technology to power counter-measures or through carful intervention by the state.

\section{III.i Algorithmic Collusion Incubator}

To explore the validity and effectiveness of several of the counter-measures, the competition agencies can begin commissioning (or internally conducting) experiments with pricing algorithms. One way is if an agency examined the available pricing algorithms in the market, and then using the data and algorithms, ran simulations in a collusion incubator. ${ }^{103}$ The agency algorithms could shadow the industry's algorithms, until it was mirroring the industry responses. The agency would then test what conditions added to (or removed from) the incubator would make tacit collusion likelier and more durable. What factors destabilize tacit collusion? How do the pricing algorithms respond when a company with a similar algorithm (but different discount factor) enters the market? When do firms become mavericks (or become co-opted)? What happens when price changes decelerate? Here, the agency can see how the algorithms respond, and what factors help promote, stabilize and destabilize algorithmic tacit collusion.

\footnotetext{
103 Jin Li and Charles Plott, 'Tacit Collusion in Auctions and Conditions for Its Facilitation and Prevention: Equilibrium Selection in Laboratory Experimental Markets', available at https://www.kellogg.northwestern.edu/faculty/li/htm/Published\%20Papers/Li_Plott\%20Tacit\%20 Collusion\%20071121.pdf.
} 
Granted, such an incubator is imperfect. The incubator is relatively static and will not reflect changes in market dynamics over the long term and changes to the algorithms - a result of self-learning or human intervention. Nonetheless, these algorithmic collusion incubators can help the agencies better understand what factors are worth exploring to destabilize tacit collusion.

Let us explore some of the available options to test in the incubator.

\section{III.ii Deceleration}

If the speed and frequency of algorithms' price adjustments facilitate collusion, then one disruptive approach may include reducing the speed and frequency with which sellers can adjust prices.

This counter-measure is implemented in the fuel sector in Austria and Western Australia, where sellers are limited in their ability to match each other's price more than once a day. In reducing the number of price changes, the mechanism seeks to allow competitors to undercut the collusive price and promote a seller's reputation as a discounter. The pricing algorithms, while continually monitoring the rivals' pricing and business maneuvers, would now face a time delay in changing price. Under this scenario, the maverick—if the delay were long enough—could profit from being the first to discount.

Not surprisingly, state intervention in the market, through disruptive algorithms or other means, can lead to sub-optimal results. For instance, restrictions on the speed of price changes may result in the state preventing sellers from discounting.

An alternative would be if the government allowed price decreases to be implemented immediately, but imposed a time lag for price increases.

It would be interesting to test whether pricing algorithms, like humans, could game the system. For example, a dominant incumbent could punish the maverick by undercutting its price. The maverick could not immediately raise its price, and might be forced to discount even further. Taking this into account, the maverick's algorithm, 
before discounting, would likely calculate the probability of incumbents retaliating, its costs (including lost profits) in discounting, and the benefits (which would be slight if rivals could instantly match the maverick's lower price). The governmental pricing delay-rather than helping the maverick and consumers-would instead serve as a punishment mechanism for defecting from the supra-competitive price. In reducing the maverick's incentives to discount where retaliation is likely, the governmental pricing delay instead could foster unintentionally tacit collusion.

\section{III.iii Reducing Transparency to the buyers' advantage}

The government can target public policies that help facilitate collusion without necessarily improving the buyers' welfare. As former FTC Chair Bill Kovacic observed:

A major example is the process for opening bids in a sealed bid procurement. Bids ordinarily are unsealed in a public setting and are displayed for all offerors to observe. This procedure enables cartel participants to determine whether their coconspirators abided by the terms of their agreement to rotate bids or otherwise suppress rivalry. An obvious reform would be to permit inspection of bids by a guardian internal to the purchasing organization, such as an inspector general. This simple measure would complicate the detection of cheating by cartel members and still ensure that the winning offeror has been identified correctly. ${ }^{104}$

Another easy case is cheap talk, where sellers benefit from the information exchange, while customers do not. 105

Beyond the easy cases, one obvious challenge is fine-tuning the enforcement policy to interdict the factors responsible for the collusive equilibrium without undermining the competitive process itself. Such intervention may also lead to an arms race between sellers and buyers. The former may likely benefit from resources and

104 William E. Kovacic, 'Antitrust Policy and Horizontal Collusion in the 21st Century', 9 Loy. Consumer L. Rep. 97, 107 (1997).

105 See, e.g., Maurice E. Stucke, 'Evaluating the Risks of Increased Price Transparency', 19 Antitrust 81 (Spring 2005). 
technological advantage. With the ability to rely on advanced algorithms to change the market dynamics and the possibility to use artificial intelligence to perfect the strategy, could competition law enforcers effectively identify and target such strategies?

But transparency is not a light switch where consumers and sellers are either in the dark or sunlight. As the economic literature shows, "what matters is not what is directly observed by the firms, but what information firms can infer from available market data. When the market is stable, inferring deviations from collusive conduct is easier and requires less market data than when the market is unstable." 106 Here, testing in the algorithmic collusion incubator might enable the government to identify and fine-tune what information should be kept private to make it harder for the algorithm to infer what competitors are doing. This may prove problematic in online industries, as it may also increase consumers' search costs. Thus one potential experiment for the incubator is where pricing is conveyed only through asymmetrical price comparison websites (where customers can quickly see the competitors' prices, but the pricing information is not captured by the algorithm). ${ }^{107}$

\section{III.iv Merger Review}

Competition authorities can also focus on deterring structural changes that foster tacit collusion. As one U.S. court observed, "Tacit coordination is feared by antitrust policy even more than express collusion, for tacit coordination, even when observed, cannot easily be controlled directly by the antitrust laws. It is a central object of merger policy to obstruct the creation or reinforcement by merger of such oligopolistic

\footnotetext{
106 Ivaldi et al (n 5).

107 One risk of this approach is if the price comparison website's market power increases, to the detriment of sellers and buyers. We explore this risk in Virtual Competition.
} 
market structures in which tacit coordination can occur." 108 Thus, stronger merger control, in particular, may be an option.

As a 2017 conference organized by the University of Chicago reflected, increasing market concentration raises a host of economic, political and social concerns. ${ }^{109}$ Thus, multiple policy reasons exist to arrest the trend toward highly concentrated industries. One factor is if tacit collusion, because of algorithms, spreads beyond duopolies to markets with as many as five to six significant players. The agencies can be more sensitive to whether the elimination of a particular player would increase significantly the risk of algorithmic tacit collusion. It may be preserving a market of diverse sellers with different horizons for profits and different capacity constraints.

One avenue is the target firm's discount rate. Firms can sustain collusion when the weight they put on future profits, measured by their discount factor, is above a certain threshold. For example, if the firm's discount factor is zero, then the firm needs and wants the money now (via discounts) rather than the profits from tacit collusion. As two economists noted, "One of the few broad generalizations that can be made from the repeated-game model of collusion is that collusive stability is inversely related to the discount rate. A collusive equilibrium that can be supported at one discount rate, above some critical level, will be unsustainable at a rate below that critical level... Firm-level changes in the discount rate may also affect cartel stability. For example, a firm's rate of time preference may change if its financing shifts to depend more heavily on debt relative to equity. The increased reliance on debt requires fixed payments to lenders, reducing the firm's discretion and increasing its need for cash flow in the short run." 110 Collusion, tacit or express, is sustainable "if and only if firms put sufficient weight on future profits, i.e., if their discount factor is not too small."111

108 F.T.C. v. H.J. Heinz Co., 246 F.3d 708, 725 (D.C. Cir. 2001) (quoting 4 Phillip E. Areeda, Herbert Hovenkamp and John L. Solow, Antitrust Law 901b2, at 9 (rev. ed.1998)).

109 Videos of the panels are available at https://research.chicagobooth.edu/stigler/events/singleevents/march-27-2017. See also Ezrachi, Sponge.

${ }^{110}$ Levenstein and Suslow (n 19).

111 Ivaldi et al (n 5): "What is robust is that "no collusion" is sustainable if firms are highly 
Thus, if the acquired firm's discount factor deviates below the critical threshold, it may be effectively thwarting tacit collusion (or at least would be willing to do so if other countermeasures were in place).

So, if firm-specific discount rates are relevant for cartel stability, ${ }^{112}$ the agency could ascertain in the incubator what happens when these firms are acquired. Moreover, firm-level changes in the discount rate may also affect cartel stability: "For example, a firm's rate of time preference may change if its financing shifts to depend more heavily on debt relative to equity. The increased reliance on debt requires fixed payments to lenders, reducing the firm's discretion and increasing its need for cash flow in the short run." 113 It is beyond the capacity or expertise for the competition authority to dictate which route (debt or equity) that the firm should undertake. But if the target's choice is between a potentially anticompetitive merger or debt, the agency can consider the potential pro-competitive benefits of debt.

The competition agency should also scrutinize conglomerate mergers when the increase in multi-market contact softens competition. ${ }^{114}$ This may arise where the same type of product or service (e.g., airlines and retail stores) is offered in different geographic markets. Also one aspect of machine learning is to discover correlations in large data sets. ${ }^{115}$ Thus, the algorithms can ascertain and respond to punishment mechanisms in distinct product markets, which to the human may appear unrelated.

impatient (very small discount factor, $\delta$ close to zero) and that "full collusion" (i.e., monopoly outcome) is sustainable when firms are very patient (large discount factor, $\delta$ close to 1 ). There would thus exist two thresholds, one below which no collusion is sustainable, and one above which full collusion is sustainable. Between these two thresholds, "more collusion" is achievable as the discount factor increases, that is, firms can sustain higher prices when they have a higher discount factor.").

112 Levenstein and Suslow (n 19).

113 Ibid.

114 Federico Ciliberto and Jonathan W. William, 'Does multimarket contact facilitate tacit collusion? Inference on conduct parameters in the airline industry', RAND Journal of Economics, Vol. 45, No. 4, Winter 2014, pp. 764-791.

115 Shirley Pepke, 'Machine learning reveals correlations of gene expression and outcomes in ovarian cancer', BMC Series Blog (March 15 2017), available at https://blogs.biomedcentral.com/bmcseriesblog/2017/03/15/machine-learning-reveals- 
Merger control, however, won't work when other factors (such as the shift to algorithmic pricing itself, or firms exiting unilaterally) foster the tacit collusion.

\section{III.v. Increasing Likelihood of Deviation.}

Besides merger review, additional counter-measures can target market structure by facilitating entry, maverick behavior and the likelihood for deviation from the tacit agreement.

To begin with, one could explore whether promoting entry by mavericks and reducing regulatory entry barriers would destabilize algorithmic tacit collusion. Here, the algorithmic incubator can examine for particular industries whether the entry by a firm is sufficient to destabilize collusion, and, if so, for how long.

Another option may be facilitating secret deals while ensuring sufficient availability of information for consumers (to limit discrimination). Such deals - away from the market place - could allow companies to undercut the market price using direct communications with buyers. As the European Commission noted, markets "need to be sufficiently transparent to allow the coordinating firms to monitor to a sufficient degree whether other firms are deviating, and thus know when to retaliate." 116 The degree of transparency, the Commission noted "often depends on how market transactions take place in a particular market." 117 The key element when evaluating the level of market transparency "is to identify what firms can infer about the actions of other firms from the available information."118

correlations-of-gene-expression-and-outcomes-in-ovarian-cancer/ (noting that their machine learning method called Correlation Explanation was "especially good at detecting weak correlations in large sets of variables, and this is likely why it was able to detect this particular pattern for the first time in ovarian cancer expression data").

116 EC Merger Guidelines (n 6), para 49.

117 EC Merger Guidelines (n 6), para 50.

118 EC Merger Guidelines (n 6), para 50: "The speed with which deterrent mechanisms can be implemented is related to the issue of transparency. If firms are only able to observe their competitors' actions after a substantial delay, then retaliation will be similarly delayed and this may influence whether it is sufficient to deter deviation." Ibid para 53. 
The government may explore, for example, whether reverse bids or giving buyers call options on multiple sellers help destabilize seller tacit collusion. ${ }^{119}$ Here the buyer, but not the rivals, learns the price of each seller for a future order. For example, rather than creating an app that simply tells you (and each competitor) the price of gas at nearby stations, one could create an app where the consumers (or their selfdriving cars) simply say, "Need gas." Each station then can offer the consumer the best price. Your app signals your demand, the competing neighboring gas stations offer their best quote, and the competing bid information (and geolocation data of where you ended up buying gas) are not shared among the gas stations.

One potential risk in this approach, as we discuss above, is that it may under certain market conditions foster price discrimination or the behavioral discrimination assessed in Virtual Competition.

The algorithmic collusion incubator can test whether enabling smaller buyers to pool their orders into less frequent, less predictable larger orders yields a better price from the sellers' algorithms, in effect rewarding a seller with greater profits to deviate from the collusive regime. ${ }^{120}$

\section{III.vi Algorithmic Combat}

When algorithms and smart bots drive markets, another counter-measure may be in the form of a 'disruptive algorithm' rather than traditional enforcement. Such algorithm may be deployed to destabilize the existing equilibrium - through mixed signaling and other means - targeting the core conditions necessary to sustain conscious parallelism. State-sponsored algorithms or other mechanisms for joint

\footnotetext{
119 Ian Ayres and Eric Talley, 'Solomonic Bargaining: Dividing A Legal Entitlement to Facilitate Coasean Trade', 104 Yale L.J. 1027, 1117 (1995).

120 Paul W. Dobson and Roman Inderst, The Waterbed Effect: Where Buying and Selling Power Come Together, 2008 Wis. L. Rev. 331, 354 (2008) ("With a large order up for grabs, suppliers may be more tempted to undercut any collusive regime and offer the large buyer a discount."); but see Levenstein and Suslow (n 19): "Although large customers may be able, in principle, to destabilize cartels, in many cases they seem instead to extract concessions that reduce their incentive to do so."
} 
consumer bargaining or protection may try to undermine the collusive equilibrium or affect levels of transparency.

The idea of a maverick algorithm skewing the market signals to destabilize tacit collusion may seem appealing. But it may generate inefficiencies and distort competition. Furthermore, it would likely lead to a race between algorithms, one destabilizing while another predicting its action and engaging in counter-measures. Thus, the incubator can test multiple types of disruption, and the attendant effect on prices and consumer search costs.

A second avenue is the maxim, "It takes a computer to beat a computer." Just as humans will infrequently beat a computer poker, go, chess or checkers program, so too they, despite their best efforts, will not consistently defeat the pricing algorithm. In effect, whether shopping for gas or playing blackjack, the "house" often wins. To better the odds, consumers can rely on algorithms programmed to maximize consumer surplus. ${ }^{121}$ Professor Michal Gal explores the potential role of 'Consumer Algorithms'. ${ }^{122}$ These could assist in empowering consumers and re-balancing the welfare equation.

Thus consumer-friendly algorithms in effect will play in the incubator against seller algorithms seeking to maximize profits. Consumers may not always win, but like the AI program that beat human poker players, they might generally win over many matches. If the seller algorithms routinely beat the consumer algorithms, government enforcers can test in the incubator measures to tilt the odds in the consumer's favor. Here, the consumer algorithms - either individually or tacitly colluding - might enhance the buyers' power and reveal strategies to further disrupt tacit collusion. This counter-measure, of course, raises its own risks of distorting

121 On this point, see Gal, Michal S. and Elkin-Koren, Niva, 'Algorithmic Consumers' (August 8, 2016), available at SSRN: https://ssrn.com/abstract=2876201, Harvard Journal of Law and Technology, Vol. 30, 2017.

122 Ibid. 
competition, including oligopsony power. Still, a controlled effort to engage in algorithmic combat may serve to limit possible adverse welfare effects.

\section{III. vi Smart Regulation}

As we explore in Virtual Competition, beyond the "laissez-faire competition good, regulation bad" refrain, challenging questions await us. For instance-is the algorithm price the competitive price, or merely a fiction created by the digitalized hand? Turning to the economist Friedrich A. Hayek, we inquire whether the emergence of super-platforms - companies that dominate the digital landscapecould indicate a monumental shift toward the attainment of all knowledge. Platforms' sophisticated computer algorithms could increasingly determine the competitive market price. Data collection by leading platforms like the car-sharing app Uber, and super-platforms like Google, Apple, and Amazon, could create an economy which, for all purposes, is planned not by bureaucrats or CEOs, but by the techno-structure. If so, a subsequent question arises: if private firms can harness Big Data and Big Analytics to effectively set prices, can governments use the same tools to monitor industry prices, or even determine a competitive price? If Uber, which doesn't own any cars or employ any drivers, can determine prices, why can't the government?

Economist and policymakers over the past few years have been interested in developing screens and tools to identify industries where cartels are likely operating. ${ }^{123}$ Thus, one avenue to explore is harnessing Big Data and Big Analytics to identify algorithmic tacit collusion. This might be attractive where the price is significantly determined by a baseline price (such as crude oil price for gasoline) and

123 'Ex officio cartel investigations and the use of screens to detect cartels', OECD Competition Committee (July 7 2014), available at https://www.oecd.org/daf/competition/exofficio-cartelinvestigation-2013.pdf (identifying two general screening approaches: i) a structural approach, which includes the analysis of structural and product characteristics of a specific market or industry that make successful collusive strategies more likely; and ii) a behavioural approach, which includes the identification through screening of firms' behaviour or market outcomes that may be the outcome by a collusive strategy). 
the other explanatory variables for price are observable. The legal obstacles in legally challenging the tacit collusion under the current law remain. But the screening tools can help policymakers prioritize the industries to test in the incubator and the likely effects of various counter-measures.

A slightly more intrusive measure is to post a "competitive" bench price. For example, the government can provide the gas apps with a "competitive" baseline price for gas, from which customers can compare how much each gas station is charging above or below that price. One risk is getting the competitive benchmark price wrong and its susceptibility to being gamed (and inflated).

\section{Concluding Remarks}

As dynamic pricing yields a competitive advantage, we are witnessing more firms turning to pricing algorithms. With so much additional profits at stake and the ability to affect the market dynamic, it is no surprise that algorithmic price optimization is attracting heavy investments. Ironically, even if some companies yearn for the days of printed list prices and secretive discounts, they may switch to pricing algorithms to prevent being at a competitive disadvantage.

As enforcers and policymakers increasingly recognize, the current antitrust enforcement toolbox is limited in effectively deterring algorithm-driven tacit collusion and behavioural discrimination. ${ }^{124}$ They recognize the difficulties and risks in finetuning the enforcement policy aimed at condemning "excessive" market transparency. Similarly, active intervention through 'good' algorithms may distort competition. This may be particularly challenging when the information and data are

\footnotetext{
124 John Naughton, 'How do you throw the book at an algorithm?', The Guardian (December 4 2016), available at https://www.theguardian.com/commentisfree/2016/dec/04/how-do-you-throw-bookat-an-algorithm-internet-big-data.
} 
otherwise available to consumers and traders and it is the intelligent use of that information that facilitates conscious parallelism.

On a positive note, many enforcers, judges, and policymakers, with whom we met, appeared engaged and willing to meet the challenge. Since we were often asked, What are we going to do about it?, we offer here several measures, including the tacit collusion incubator. Nothing we propose is the elixir to deter algorithmic tacit collusion (or the behavioral exploitation and hybrid collusion/discrimination) scenarios. Nonetheless, these measures-in widening the toolbox-can bring us closer in deterring the anticompetitive scenarios.

Of course, any enforcement action must account the costs of over-intervention. Yet, the cost of under-intervention must also be acknowledged. Consumers and enforcers with the current tools cannot blunt the siren song of profits from algorithmic tacit collusion. Brick-and-mortar shops are closing at a faster rate. As they migrate to the online world, they, like OK Benzin, will likely seek to maximize profits. To do so, they, like OK Benzin, will turn to algorithms to improve their pricing analysis and lower the cost of price wars or better yet, to avoid them altogether. No one will say tacit collusion. The marketing message will be subtler-such as optimizing prices through AI—but the end game is the same, namely supra-competitive profits.

So one cannot assume that market forces alone will yield the benefits of the datadriven economy while mitigating the risks. Further, one cannot assume that one agency can do the job. To effectively tackle our hybrid collusion/behavioral exploitation scenario, for example, we need greater coordination among the privacy, consumer protection and competition authorities. So the aim for policymakers in the EU, US and elsewhere, remains the same: to develop an inclusive data-driven economy that benefits more than $1 \%$ of the population. 